\title{
New next-generation microwave thermosphere ablation for small hepatocellular carcinoma
}

Hideyuki Tamai and Jumpei Okamura

Department of Hepatology, Wakayama Rosai Hospital, Wakayama, Japan

Graphical Abstract
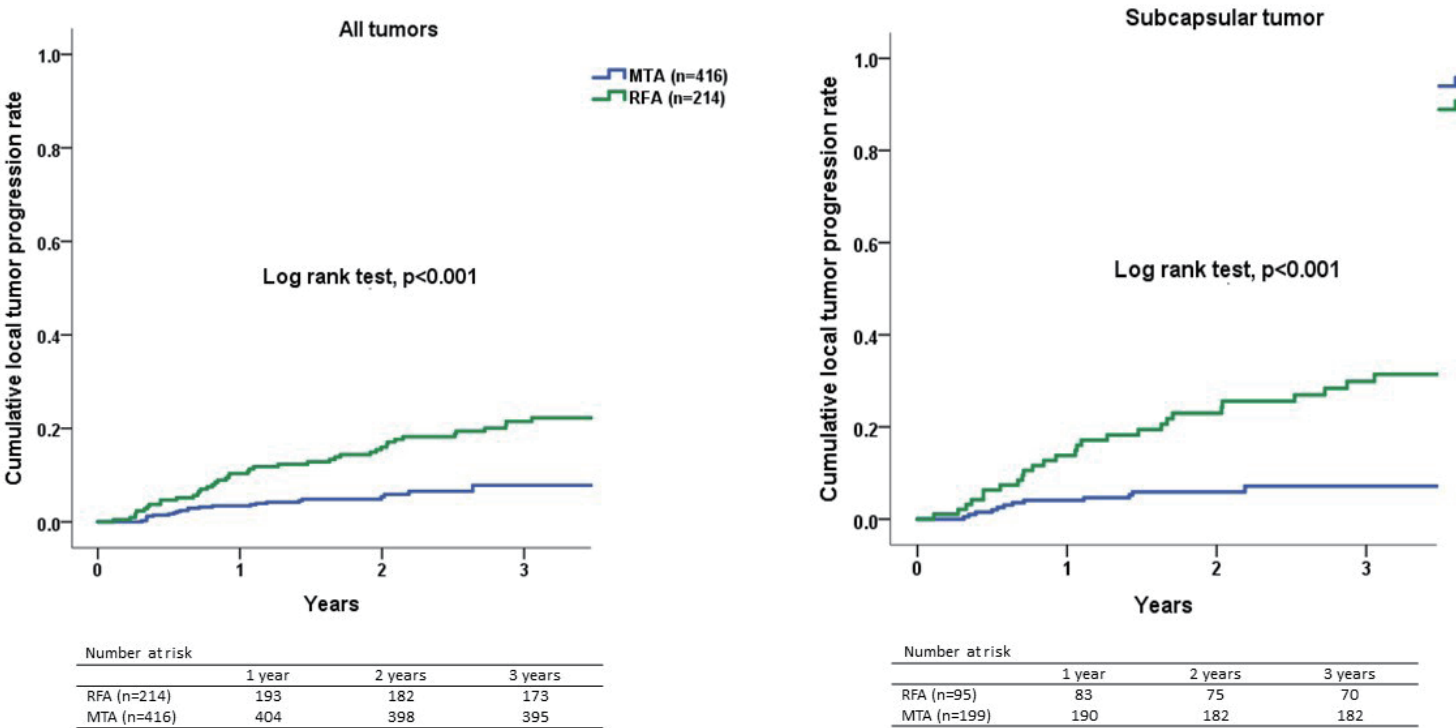

\begin{tabular}{lccc} 
Number at risk & & & \\
\hline & 1 year & 2 years & 3 years \\
\hline RFA $(n=95)$ & 83 & 75 & 70 \\
MTA $(n=199)$ & 190 & 182 & 182 \\
\hline
\end{tabular}

\section{Abbreviations:}

AFP, alpha-fetoprotein; CECT, contrast-enhanced computed tomography; CEUS, contrast-enhanced ultrasonography; $\mathrm{Cl}$, confidence interval; HBV, hepatitis B virus; HCC, hepatocellular carcinoma; HR, hazard ratio; MRI, magnetic resonance imaging; MTA, microwave thermosphere ablation; MWA, microwave ablation; RFA, radiofrequency ablation
Corresponding author : Hideyuki Tamai

Department of Hepatology, Wakayama Rosai Hospital, 93-1 Kinomoto, Wakayama 640-8505, Japan

Tel: +81-73-451-3181, Fax: +81-73-452-7171

E-mail:hdy-tamai@wakayamah.johas.go.jp

https://orcid.org/0000-0003-4511-4573 
Background/Aims: In July 2017, the Emprint ${ }^{\mathrm{TM}}$ next-generation microwave ablation system using thermosphere technology (Covidien, Boulder, CO, USA) was approved for use in Japan. This system can produce a predictable spherical ablation zone at higher temperatures than radiofrequency ablation (RFA). The aim of the present study was to elucidate whether this new microwave thermosphere ablation (MTA) could safely improve outcome compared to RFA, which is the standard of care for small hepatocellular carcinoma (HCC).

Methods: This retrospective study analyzed 513 patients with $630 \mathrm{HCCs}(\leq 3 \mathrm{~cm})$ who were performed by percutaneous RFA (174 patients, 214 HCCs) or MTA (339 patients, 416 HCCs) between January 2016 and March 2020.

Results: Median ablation time was significantly shorter for MTA (240 seconds) than for RFA (721 seconds; $P<0.001)$. A significant difference in 3-year local tumor progression rate was evident between the RFA group (22\%) and MTA group $(8 \% ; P<0.001)$. Multivariable analysis revealed ablation procedure and tumor diameter as independent factors contributing to local tumor progression (MTA; $P<0.001$; hazard ratio, $0.565 ; 95 \%$ confidence interval, $0.437-0.731$ ). In patients with primary HCC, a significant difference in overall survival was evident (RFA vs. MTA, 3-year, $77 \%$ vs. $95 \%, P=0.029$ ). Ablation procedure and Child-Pugh score were independent factors contributing to survival. The total complication rate was significantly lower for MTA (8\%) than for RFA $(14 \%, P<0.05)$, particularly for bile duct injury ( $3 \%$ vs. $9 \%$, respectively; $P<0.05)$.

Conclusions: Next-generation MTA for small HCC could provide safer, more curative treatment in a shorter ablation time than RFA. (Clin Mol Hepatol 2021;27:564-574)

Keywords: Carcinoma, Hepatocellular; Radiofrequency ablation; Microwaves

\footnotetext{
Study Highlights

Next-generation MTA using the Emprint ${ }^{\mathrm{TM}}$ ablation system can produce a predictable spherical ablation zone at higher temperatures than RFA. The present study demonstrated that MTA for small HCC provided safer, more curative treatment than RFA within a shorter ablation time, and may improve prognosis. MTA can also reduce the burden on not only patients, but also medical staff through this shorter ablation time. MTA has potential to replace RFA for small HCC.
}

\section{INTRODUCTION}

Percutaneous local treatment with radiofrequency ablation (RFA) is the current standard of care for patients with early-stage hepatocellular carcinoma (HCC) unsuitable for surgical resection. Recently, overall survival rates for HCC less than $3 \mathrm{~cm}$ in diameter treated using RFA or surgical resection have been reported as comparable. ${ }^{1}$ RFA is indicated for patients with up to three HCCs $\leq 3 \mathrm{~cm}$ in diameter and Child-Pugh class A or B liver function., ${ }^{2,3}$ However, the curability of RFA depends on its location. For example, a perivascular location has a high risk of incomplete ablation because of the heat sink effect in which cooling is provided by blood flow through vessels adjacent to the tumor. ${ }^{4,5}$ As a result, the local tumor progression rate after RFA is approximately 30\% at 3 years. ${ }^{2}$ This level is insufficient for curative treatment. A more curative ablation procedure is thus required.

Microwave ablation (MWA) is another percutaneous thermal ablation therapy. In comparison with RFA, MWA offers the advan- tages of faster heating and less susceptibility to heat sink effects because higher temperatures are generated. ${ }^{6}$ However, conventional MWA shows some major disadvantages. First, the ablation zone shows a teardrop shape. For that reason, MWA carries a high risk of thermal damage to the subcutaneous tissues and skin in ablation of the subcapsular tumor, especially with the development of systems with greater power. ${ }^{6}$ Second, the ablation size is unpredictable with changes in surrounding tissues. ${ }^{6}$ To overcome these disadvantages, Emprint ${ }^{\mathrm{TM}}$ (Covidien, Boulder, CO, USA) was developed as a new, next-generation MWA system with thermosphere technology. Microwave thermosphere ablation (MTA) is able to create predictable spherical zones of ablation by incorporating thermal control, field control, and wavelength control technologies into the system. ${ }^{7}$ Vogl et al. ${ }^{8}$ demonstrated that larger minimal ablative margins can be obtained by MTA in comparison to two routinely used conventional MWA systems. MTA is thus expected to safely improve local tumor control compared to RFA. This system was approved for use in the United States in April 


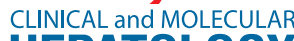

\section{HEPATOLOGY}

Volume_27 Number_4 October 2021

2014, and for use in Japan in July 2017. The aim of the present study was to elucidate whether this new, next-generation MTA could safely improve outcome compared to RFA.

\section{PATIENTS AND METHODS}

\section{Patients}

The sample size for this retrospective cohort study was determined from our database of percutaneous ablation therapy for HCC during the study period. Between January 2016 and March 2020, a total of 573 consecutive patients with 702 HCCs were treated by percutaneous thermal ablation in our hospital. We introduced MTA in December 2017, and replaced RFA with MTA from September 2018. RFA was performed from January 2016 to August 2018. Of the 573 patients with 702 HCCs, 23 patients with $33 \mathrm{HCCs}$ received palliative ablation due to advanced stage, four patients with four HCCs were lost to follow-up after ablation, and two patients with two HCCs showing Child-Pugh class C liver function were excluded from the present study. Another 31 patients with 32 HCCs showing maximum tumor diameter $>3 \mathrm{~cm}$ were excluded. Finally, 513 patients with $630 \mathrm{HCCs}(\leq 3 \mathrm{~cm})$ were classified into a group receiving RFA (174 patients with 214 HCCs) and a group receiving MTA (339 patients with 416 HCCs). Patient flow in this study is shown in Figure 1. HCC was diagnosed based on typical findings of HCC on contrast-enhanced computed to- mography (CECT), dynamic magnetic resonance imaging (MRI), and/or contrast-enhanced ultrasonography (CEUS). ${ }^{3}$ Ablation time, local tumor progression rate, and complications were compared between MTA and RFA. To identify factors affecting local tumor progression, ablation modality and tumor location were also analyzed. Perivascular tumor was defined as a tumor adjacent to vessels $\leq 3 \mathrm{~mm}$ in diameter. ${ }^{9}$ In addition, overall survival and recurrence-free survival in patients with primary HCC were also analyzed. HCC patients with no history of HCC treatments were considered to represent patients with primary HCC.

This study was approved by the Ethics Committee at Wakayama Rosai Hospital. The need to obtain written informed consent was waived, due to the retrospective nature of the study.

\section{Ablation technique}

A Cool-tip ${ }^{T M}$ RF system (Covidien) with a 17-gauge, cooled-tip electrode and a 2- or 3-cm non-insulated tip was used for RFA. An Emprint ${ }^{\mathrm{TM}}$ ablation system with a 13-gauge standard antenna (20-cm long) was used for MTA. Both procedures were performed under ultrasound guidance. Artificial pleural effusion or ascites was prepared using saline if needed. RFA was performed under the impedance control mode. Electric power was set at $40 \mathrm{~W}$ for the 2-cm electrode or $60 \mathrm{~W}$ for the 3-cm electrode, and was elevated at a rate of $10 \mathrm{~W} / \mathrm{min}$. When an impedance out occurred, output was automatically stopped, and ablation was resumed at $10 \mathrm{~W}$ lower than the output power at the time of impedance out.

HCC patients treated by RFA or MTA between January 2016 and March 2020 (573 patients, 702 tumors)

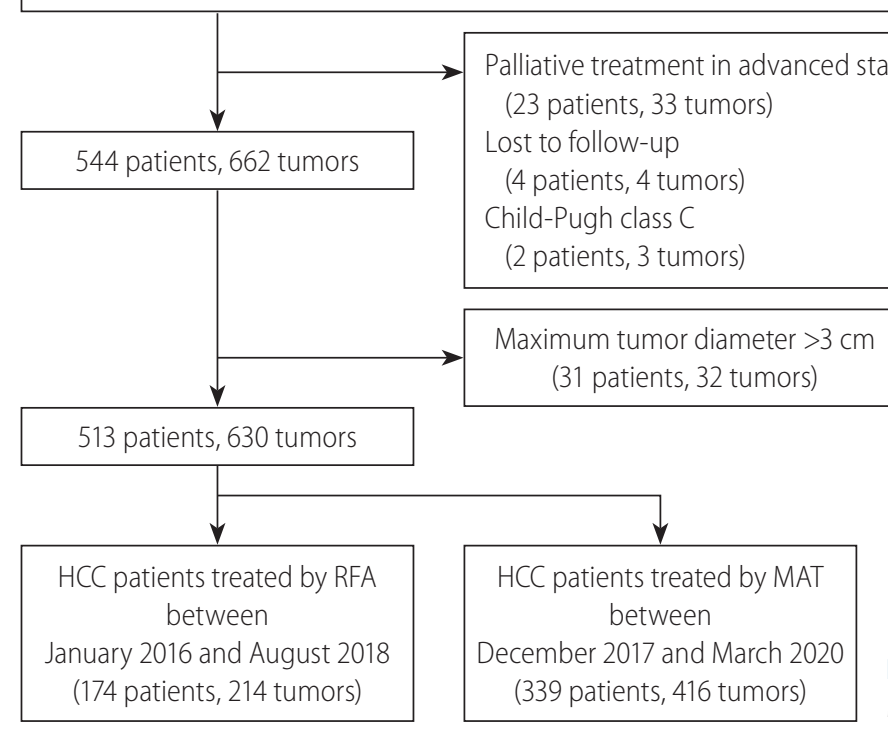

Figure 1. Flow chart for the study. HCC, hepatocellular carcinoma; MTA, microwave thermosphere ablation; RFA, radiofrequency ablation. 
Duration time of RFA was set at 6 minutes for the 2-cm electrode and 12 minutes for the $3-\mathrm{cm}$ electrode. Additional ablation was performed if the temperature was below $65^{\circ} \mathrm{C}^{10}$ In MTA, output power was set at $100 \mathrm{~W}$, and duration time was 1-2 minutes for a 2-cm ablation zone, and 3-4 minutes for a 3-cm ablation zone. When the target tumor was entirely covered by a transient hyperechoic zone, both RFA and MTA treatments were finished. Needle track ablation was not performed in either procedure, to prevent seeding and hemorrhage. After taking out the electrode or antenna from the liver, the needle track was observed using color Doppler or CEUS. If hemorrhage from the needle track increased rapidly, we stopped bleeding by percutaneous ethanol injection. ${ }^{10}$

\section{Evaluation of treatment efficacy and follow-up}

Treatment efficacy was evaluated on CECT or MRI at 1-3 days after the ablation procedure. Complete ablation was defined as no tumor enhancement with a safety margin $(\geq 5 \mathrm{~mm})$. If the safety margin was judged as insufficient, ablation was added within 1 month after treatment. In principle, all patients were followedup by CECT or dynamic MRI every 3-4 months.

\section{Evaluation of outcomes after ablation}

The primary endpoint of the present study was local tumor progression, representing treatment failure. Local tumor progression was defined as tumor growth touched inside or outside the postablation zone.

\section{Safety evaluation}

To evaluate the safety of ablation therapy, the profiles and incidences of complications were compared between RFA and MTA groups. Major complications were defined as events leading to

Table 1. Comparison of baseline characteristics between radiofrequency ablation and microwave thermosphere ablation groups

\begin{tabular}{|c|c|c|c|c|}
\hline & $\begin{array}{c}\text { Overall } \\
\text { (513 patients, } 630 \text { tumors) }\end{array}$ & $\begin{array}{c}\text { RFA group } \\
\text { (174 patients, } 214 \text { tumors) }\end{array}$ & $\begin{array}{c}\text { MTA group } \\
\text { (339 patients, } 416 \text { tumors) }\end{array}$ & $P$-value \\
\hline Age (years) & $74(36-90)$ & $74(53-89)$ & $75(36-90)$ & 0.155 \\
\hline Sex, male/female & $364 / 149$ & $122 / 52$ & $242 / 97$ & 0.764 \\
\hline Etiology, HBV/HCV/non-virus & 46/315/152 & 14/123/37 & $32 / 192 / 115$ & 0.006 \\
\hline Liver cirrhosis & $358(70.0)$ & $134(77.0)$ & $224(66.0)$ & 0.011 \\
\hline Child-Pugh score & $5(5-9)$ & $5(5-9)$ & $5(5-9)$ & 0.675 \\
\hline Child class, A/B & $464 / 49$ & $159 / 15$ & $305 / 34$ & 0.607 \\
\hline Esophageal varices & $186(36.0)$ & $74(43.0)$ & $112(33.0)$ & 0.034 \\
\hline Extrahepatic shunt & $115(22.0)$ & $30(17.0)$ & $85(25.0)$ & 0.044 \\
\hline Platelets $\left(\times 10^{4} / \mathrm{mm}^{3}\right)$ & $13.8(3.1-38.4)$ & $12.7(3.5-32.9)$ & $14.3(3.1-38.4)$ & 0.059 \\
\hline $\operatorname{ALT}(\mathrm{U} / \mathrm{L})$ & $21(4-189)$ & $24(4-189)$ & $20(8-120)$ & 0.012 \\
\hline Onset, primary/recurrence & $132 / 381$ & $41 / 133$ & $91 / 248$ & 0.421 \\
\hline Tumor diameter (mm) & $15(5-30)$ & $15(7-30)$ & $15(5-30)$ & 0.407 \\
\hline Number of tumors & $1(1-4)$ & $1(1-4)$ & $1(1-4)$ & 0.547 \\
\hline TNM stage, I/II/III & $352 / 137 / 24$ & $115 / 52 / 7$ & 237/85/17 & 0.476 \\
\hline Perivascular tumors & $152(24.0)$ & $37(17.0)$ & $115(28.0)$ & 0.004 \\
\hline Subcapsular tumors & $294(47.0)$ & $95(44.0)$ & $199(48.0)$ & 0.412 \\
\hline Exophytic tumors & $53(8.0)$ & $17(8.0)$ & $36(9.0)$ & 0.761 \\
\hline Tumors adjacent to other organs & $75(12.0)$ & $19(9.0)$ & $56(13.0)$ & 0.093 \\
\hline $\operatorname{AFP}(\mathrm{ng} / \mathrm{mL})$ & $6.0(0.7-1,087.0)$ & $6.9(0.7-1,087.0)$ & $5.5(0.7-983.0)$ & 0.044 \\
\hline $\mathrm{DCP}(\mathrm{mAU} / \mathrm{mL})$ & $30(5-4,267)$ & $35(6-3,546)$ & $29(5-4,267)$ & 0.236 \\
\hline
\end{tabular}

Values are presented as median (range) or number (\%) unless otherwise indicated.

RFA, radiofrequency ablation; MTA, microwave thermosphere ablation; HBV, hepatitis B virus; $H C V$, hepatitis C virus; ALT, alanine aminotransferase; TNM, tumor node metastasis; AFP, alpha-fetoprotein; DCP, des-gamma-carboxyprothrombin. 
substantial morbidity or disability, increasing the level of care, or resulting in hospital admission or substantially extended hospital stay. ${ }^{11}$

\section{Statistical analysis}

Values are expressed as median and range. The Mann-Whitney $U$ test was used to analyze continuous variables. Fisher's exact test or the chi-squared test was used to analyze categorical variables. The cumulative rates of local tumor progression, recurrence-free survival, and overall survival were evaluated using Kaplan-Meier methods. The statistical significance of differences between groups was examined using log-rank tests. Factors contributing to local tumor progression and survival were analyzed using Cox proportional hazards regression models. Factors showing a result of $P<0.05$ in univariable analyses were entered into the multivariable analysis. Results were expressed as hazard ratios (HRs) and 95\% confidence intervals (Cls). Values of $P<0.05$ were considered significant. All analyses were performed using SPSS version 24.0 software (SPSS, Chicago, IL, USA).

\section{RESULTS}

\section{Patient characteristics}

Patient characteristics are summarized in Table 1. Proportions of non-viral hepatitis, extrahepatic shunt, and perivascular tumor were significantly higher in MTA than in RFA. Conversely, proportions of liver cirrhosis and esophageal varices, and levels of alphafetoprotein (AFP) and alanine aminotransferase were significantly lower in MTA than in RFA. However, no significant differences were seen in other baseline factors such as age, sex, onset, tumor size, number of tumors, TNM stage, liver function, platelets count, desgamma-carboxyprothrombin level, or other tumor location. Of the 46 patients infected with hepatitis B virus (HBV), 39 patients re-

Table 2. Comparison of baseline characteristics in patients with primary hepatocellular carcinoma between radiofrequency ablation and microwave thermosphere ablation groups

\begin{tabular}{|c|c|c|c|c|}
\hline & Overall (132 patients) & RFA group (41 patients) & MTA group (91 patients) & $P$-value \\
\hline Age (years) & $74(36-90)$ & $74(53-88)$ & $74(36-90)$ & 0.881 \\
\hline Sex, male/female & $89 / 43$ & $28 / 13$ & $61 / 30$ & 0.886 \\
\hline Etiology, HBV/HCV/non-virus & $9 / 61 / 62$ & $3 / 21 / 17$ & $6 / 40 / 45$ & 0.695 \\
\hline Liver cirrhosis & $87(66.0)$ & $32(78.0)$ & $55(60.0)$ & 0.048 \\
\hline Child-Pugh score & $5(5-9)$ & $5(5-9)$ & $5(5-9)$ & 0.833 \\
\hline Child class, A/B & $113 / 19$ & $37 / 4$ & $76 / 15$ & 0.424 \\
\hline Esophageal varices & $47(36.0)$ & $18(44.0)$ & $29(32.0)$ & 0.181 \\
\hline Extrahepatic shunt & $34(26.0)$ & $6(15.0)$ & $28(31.0)$ & 0.055 \\
\hline Platelets $\left(\times 10^{4} / \mathrm{mm}^{3}\right)$ & $14.2(3.5-30.9)$ & $14.1(3.5-30.0)$ & $14.8(4.2-30.9)$ & 0.516 \\
\hline $\operatorname{ALT}(\mathrm{U} / \mathrm{L})$ & $25(9-120)$ & $25(9-92)$ & $24(9-120)$ & 0.817 \\
\hline Tumor diameter (mm) & $20(8-30)$ & $20(10-30)$ & $20(8-30)$ & 0.699 \\
\hline Number of tumors & $1(1-3)$ & $1(1-2)$ & $1(1-3)$ & 0.547 \\
\hline TNM stage, I/II/III & $78 / 46 / 8$ & $22 / 17 / 2$ & $56 / 29 / 6$ & 0.554 \\
\hline Perivascular tumors & $35(27.0)$ & $9(22.0)$ & $26(29.0)$ & 0.425 \\
\hline Subcapsular tumors & $62(47.0)$ & $21(51.0)$ & $41(45.0)$ & 0.511 \\
\hline Exophytic tumors & $9(7.0)$ & $2(5.0)$ & $7(8.0)$ & 0.720 \\
\hline Tumors adjacent to other organs & $14(11.0)$ & $4(10.0)$ & $10(11.0)$ & 1.000 \\
\hline AFP $(\mathrm{ng} / \mathrm{mL})$ & $6.0(0.7-983)$ & $8.0(0.7-454.0)$ & $4.6(1.0-983.0)$ & 0.025 \\
\hline $\mathrm{DCP}(\mathrm{mAU} / \mathrm{mL})$ & $27(5-4,267)$ & $35(10-760)$ & $26(5-4,267)$ & 0.472 \\
\hline
\end{tabular}

Values are presented as median (range) or number (\%) unless otherwise indicated.

RFA, radiofrequency ablation; MTA, microwave thermosphere ablation; HBV, hepatitis B virus; HCV, hepatitis C virus; ALT, alanine aminotransferase; TNM, tumor node metastasis; AFP, alpha-fetoprotein; DCP, des-gamma-carboxyprothrombin. 
ceived nucleoside analogue therapy. However, seven patients did not receive anti-viral therapy because of negative results for serum HBV-DNA. Of the 316 patients identified as infected with hepatitis C virus, the infection was eradicated in 312 patients using direct-acting antivirals. Comparisons of baseline characteristics in patients with primary HCC are shown in Table 2. The proportion of liver cirrhosis and AFP level were both significantly lower with MTA than with RFA.

Median ablation time was significantly shorter for MTA (240 seconds; range, 60-1,140) than for RFA (721 seconds; range,
240-2,880; $P<0.001)$. Preparation rates of artificial pleural effusion before RFA and MTA were 41\% (71/174) and 39\% (133/339), respectively $(P=0.731)$. Preparation rates of artificial ascites were $5 \%(9 / 174)$ and $4 \%(13 / 339$, respectively $(P=0.479)$. No significant differences in preparation rates of artificial pleural or ascites were identified between groups. Complete ablation rate after first treatment was 98\% (210/214) for RFA and 96\% (401/416) for MTA. No significant difference in complete ablation rate was apparent between groups $(P=0.326)$. The technical success rate was $100 \%$ in both groups, because all patients were finally
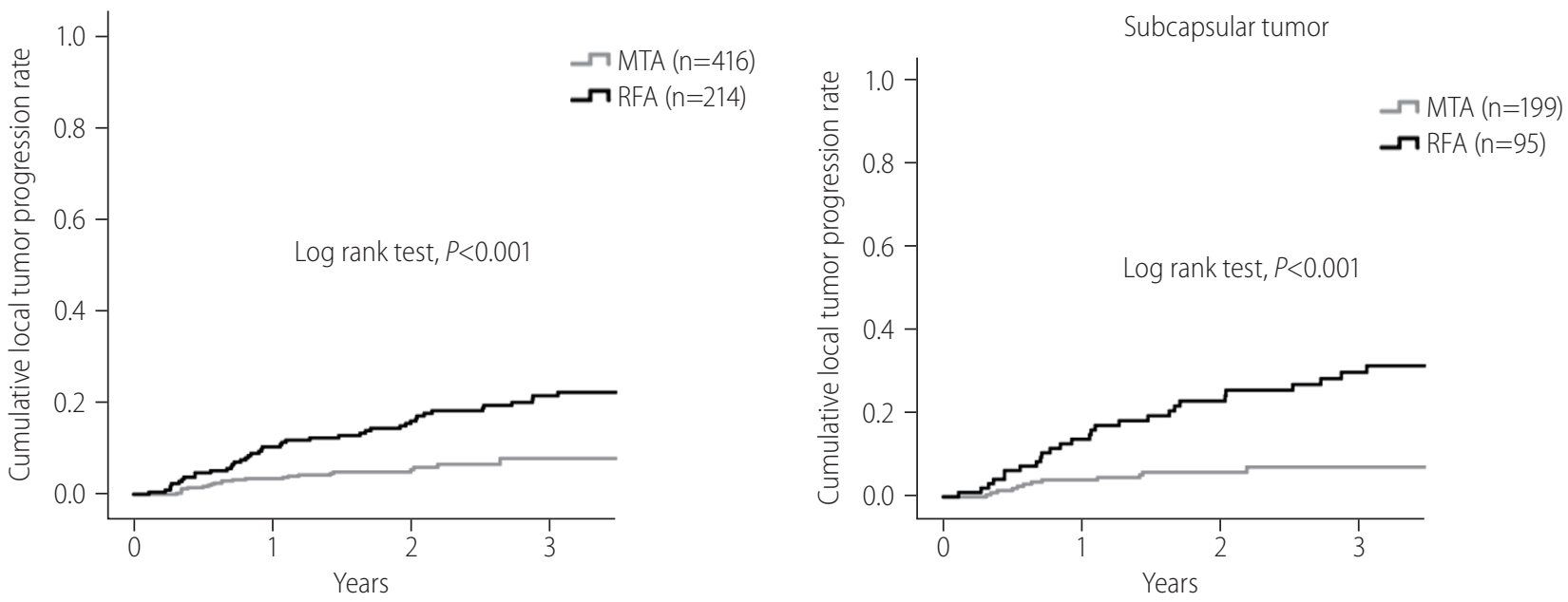

Number at risk

\begin{tabular}{lccc}
\hline & 1 year & 2 years & 3 years \\
\hline RFA $(n=214)$ & 193 & 182 & 173 \\
\hline MTA $(n=416)$ & 404 & 398 & 395 \\
\hline
\end{tabular}

Number at risk

\begin{tabular}{lccc}
\hline & 1 year & 2 years & 3 years \\
\hline RFA $(n=95)$ & 83 & 75 & 70 \\
\hline MTA $(n=199)$ & 190 & 182 & 182 \\
\hline
\end{tabular}

Perivascular tumor

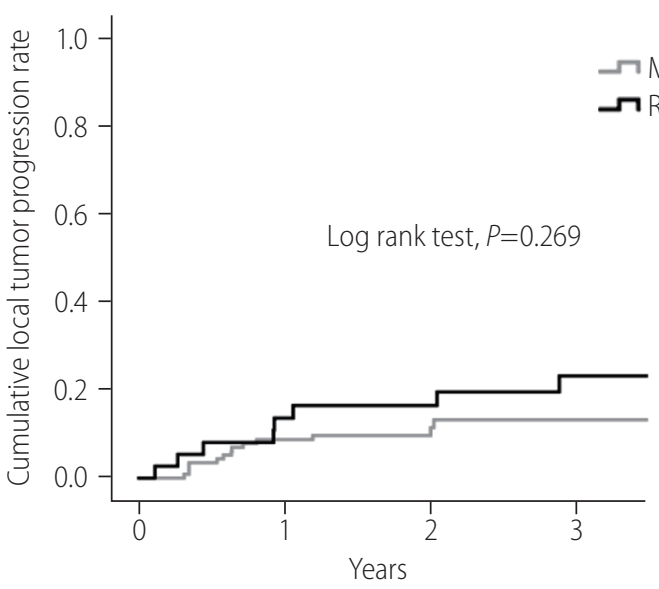

$\neg$ MTA $(n=115)$

$\boldsymbol{R}$ RFA $(\mathrm{n}=37)$

Number at risk

\begin{tabular}{lccc}
\hline & 1 year & 2 years & 3 years \\
\hline RFA $(n=37)$ & 32 & 31 & 29 \\
\hline MTA $(n=115)$ & 107 & 105 & 104 \\
\hline
\end{tabular}

Figure 2. (A) Comparison of cumulative local tumor progression curves between radiofrequency ablation (RFA) and microwave thermosphere ablation (MTA) groups. A significant difference is apparent between groups $(P<0.001)$. Three-year local tumor progression rates for RFA and MTA groups are $22 \%$ and $8 \%$, respectively. (B) Comparison of cumulative local tumor progression curves between RFA and MTA in subcapsular hepatocellular carcinomas (HCCs). A significant difference is evident between groups (RFA vs. MTA, 3-year, 30\% vs. $7 \%$, $P<0.001$ ). (C) Comparison of cumulative local tumor progression curves between RFA and MTA for perivascular HCCs. No significant difference is evident between groups (RFA vs. MTA, 3-year, $23 \%$ vs. $13 \%, P=0.269$ ). 


\section{CLINCAL and MOLECULAR}

Volume_27 Number_4 October 2021

judged as having achieved complete ablation by additional abla1,358 days (range, 316-1,834) and 738 days (range, 285-1,291), tion. Median follow-up period for the RFA and MTA groups was respectively.
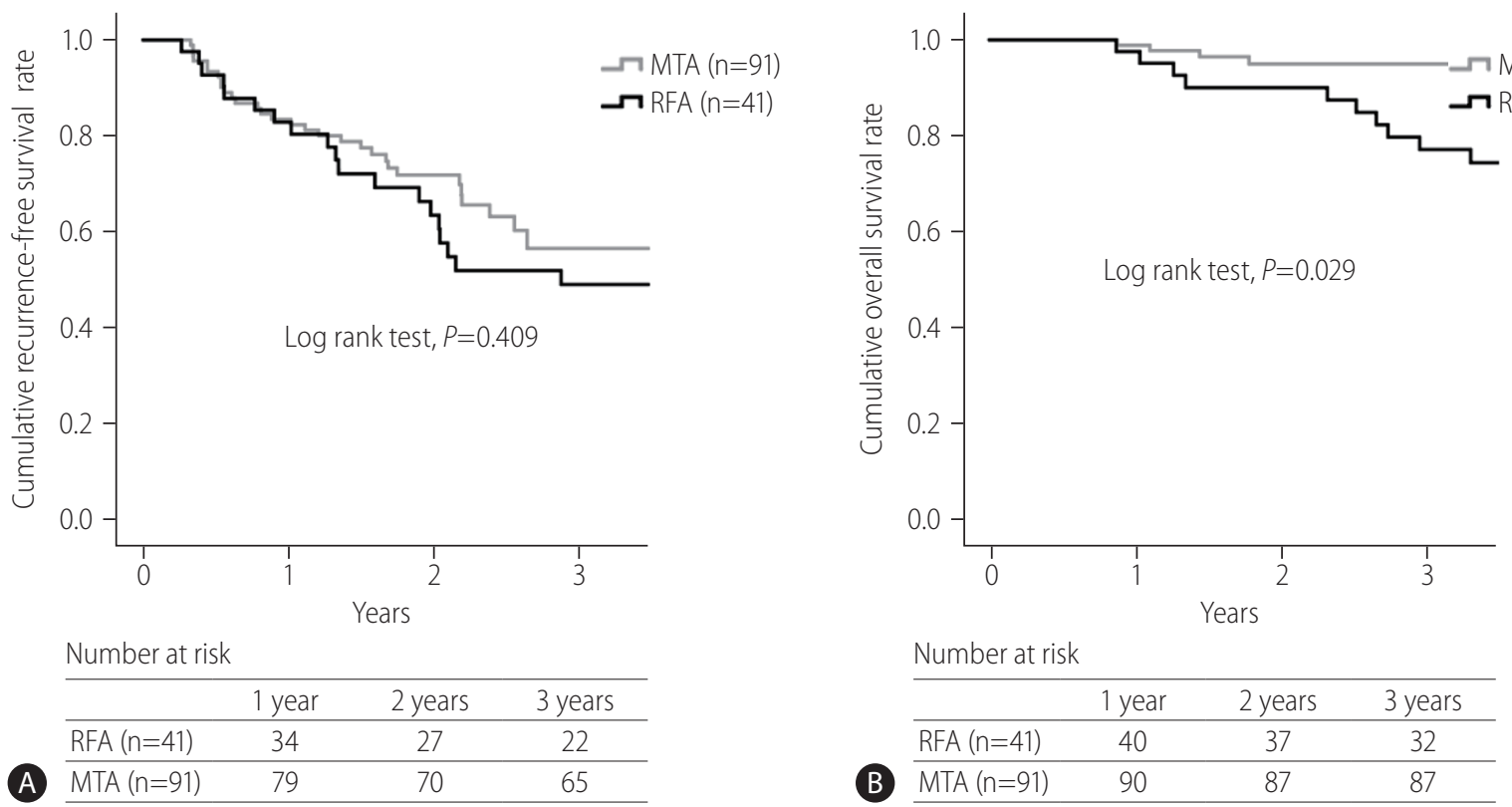

Number at risk

A \begin{tabular}{lccc}
\hline & year & 2 years & 3 years \\
\hline RFA $(n=41)$ & 34 & 27 & 22 \\
\hline MTA $(n=91)$ & 79 & 70 & 65 \\
\hline
\end{tabular}

Figure 3. (A) Comparison of cumulative recurrence-free survival curves in patients with primary hepatocellular carcinoma (HCC). No significant difference is seen in recurrence-free survival between radiofrequency ablation (RFA) and microwave thermosphere ablation (MTA) groups (RFA vs. MTA, 3 -year, $49 \%$ vs. $57 \%, P=0.409$ ). (B) Comparison of cumulative overall survival curves in patients with primary HCC. A significant difference is evident in overall survival (RFA vs. MTA, 3-year, $77 \%$ vs. 95\%, $P=0.029$ ).

Table 3. Uni- and multivariable analyses of factors contributing to local tumor progression

\begin{tabular}{|c|c|c|c|c|}
\hline \multirow{2}{*}{ Variable } & \multicolumn{2}{|c|}{ Univariable } & \multicolumn{2}{|c|}{ Multivariable } \\
\hline & $P$-value & $\mathrm{HR}(95 \% \mathrm{Cl})$ & $P$-value & HR $(95 \% \mathrm{Cl})$ \\
\hline Age (years) & 0.813 & $0.997(0.968-1.026)$ & & \\
\hline Sex, female & 0.429 & $0.797(0.454-1.399)$ & & \\
\hline Etiology, non-virus & 0.679 & $1.118(0.660-1.891)$ & & \\
\hline Onset, recurrence & 0.287 & $0.867(0.667-1.127)$ & & \\
\hline Liver cirrhosis & 0.162 & $0.697(0.420-1.156)$ & & \\
\hline Child class A & 0.952 & $0.990(0.718-1.365)$ & & \\
\hline Child-Pugh score & 0.443 & $0.672(0.244-1.852)$ & & \\
\hline Tumor diameter (mm) & $<0.001$ & $1.073(1.033-1.115)$ & 0.001 & $1.070(1.030-1.113)$ \\
\hline Ablation method, MTA & $<0.001$ & $0.334(0.200-0.559)$ & $<0.001$ & $0.565(0.437-0.731)$ \\
\hline Perivascular tumors & 0.100 & $1.545(0.921-2.595)$ & & \\
\hline Subcapsular tumors & 0.031 & $1.718(1.052-2.907)$ & 0.228 & $1.391(0.813-2.380)$ \\
\hline Exophytic tumors & 0.038 & $2.043(1.042-4.006)$ & 0.130 & $1.744(0.848-3.587)$ \\
\hline Tumors adjacent to other organs & 0.137 & $1.636(0.856-3.127)$ & & \\
\hline AFP (ng/mL) & 0.132 & $1.001(1.000-1.003)$ & & \\
\hline $\mathrm{DCP}(\mathrm{mAU} / \mathrm{mL})$ & 0.279 & $1.000(1.000-1.001)$ & & \\
\hline
\end{tabular}

$\mathrm{HR}$, hazard ratio; $\mathrm{Cl}$, confidence interval; MTA, microwave thermosphere ablation; AFP, alpha-fetoprotein; DCP, des-gamma-carboxyprothrombin. 


\section{Comparisons of local tumor progression between RFA and MTA groups}

Cumulative local tumor progression curves are compared between RFA and MTA groups in Figure 2. A significant difference was evident between groups $(P<0.001)$, and the 3-year local tumor progression rate was $22 \%$ for RFA and $8 \%$ for MTA. Cumulative local tumor progression curves between RFA and MTA groups are also compared according to tumor location in Figure 2. Al- though a significant difference between groups was identified for subcapsular HCCs (RFA vs. MTA, 3-year, $30 \%$ vs. $7 \%, P<0.001$ ), no significant difference was seen for perivascular HCCs (RFA vs. MTA, 3-year, $23 \%$ vs. $13 \%, P=0.269$ ).

Of 66 local-recurrent HCCs after RFA or MTA, 59 tumors was curatively treated by MTA $(n=46)$, RFA $(n=10)$, proton beam therapy $(n=2)$, or resection $(n=1)$. However, seven tumors were treated by transcatheter chemoembolization because of the presence of multiple intrahepatic metastatic recurrences.

Table 4. Uni- and multivariable analyses of factors contributing to survival

\begin{tabular}{|c|c|c|c|c|}
\hline \multirow{2}{*}{ Variable } & \multicolumn{2}{|c|}{ Univariable } & \multicolumn{2}{|c|}{ Multivariable } \\
\hline & $P$-value & $\mathrm{HR}(95 \% \mathrm{Cl})$ & $P$-value & $\mathrm{HR}(95 \% \mathrm{Cl})$ \\
\hline Age (years) & 0.337 & $1.028(0.972-1.087)$ & & \\
\hline Sex, female & 0.971 & $1.020(0.346-3.006)$ & & \\
\hline Etiology, non-virus & 0.436 & $1.498(0.542-4.144)$ & & \\
\hline Liver cirrhosis & 0.170 & $2.851(0.638-12.745)$ & & \\
\hline Child class A & 0.266 & $0.478(0.130-1.756)$ & & \\
\hline Child-Pugh score & 0.001 & 2.055 (1.372-3.184) & $<0.001$ & $2.361(1.456-3.828)$ \\
\hline Tumor diameter (mm) & 0.342 & $1.042(0.957-1.135)$ & & \\
\hline Number of tumors & 0.540 & $0.536(0.073-3.939)$ & & \\
\hline Ablation method, MTA & 0.039 & $0.282(0.085-0.936)$ & 0.016 & $0.205(0.056-0.747)$ \\
\hline $\operatorname{AFP}(\mathrm{ng} / \mathrm{mL})$ & 0.127 & 1.002 (0.999-1.005) & & \\
\hline $\mathrm{DCP}(\mathrm{mAU} / \mathrm{mL})$ & 0.795 & 1.000 (0.999-1.001) & & \\
\hline
\end{tabular}

HR, hazard ratio; $\mathrm{Cl}$, confidence interval; MTA, microwave thermosphere ablation; AFP, alpha-fetoprotein; DCP, des-gamma-carboxyprothrombin.

Table 5. Comparison of complications between radiofrequency ablation and microwave thermosphere ablation groups

\begin{tabular}{lccc}
\hline Complication & RFA group $(\mathbf{n}=\mathbf{1 7 4})$ & MTA group (n=339) & $\boldsymbol{P}$-value \\
\hline Total & $25(14.0)$ & $26(8.0)$ & $<0.05$ \\
Intra-abdominal or pleural hemorrhage & $8(5.0)$ & $11(3.0)$ & 0.46 \\
Liver abscess & $1(1.0)$ & $2(1.0)$ & 1.00 \\
Portal thrombosis & $0(0.0)$ & $1(1.0)$ & 0.55 \\
Biliary ductal injury & $15(9.0)$ & $0(0.0)$ & 0.01 \\
Seeding & $1(1.0)$ & $6(2.0)$ & 0.34 \\
Major complication & $4(2.0)$ & $1(0.3)$ & 0.74 \\
Intrapleural hemorrhage & $2(1.0)$ & $2(1.0)$ & 0.27 \\
Liver abscess & $1(1.0)$ & $2(1.0)$ & 1.00 \\
Portal thrombosis & $0(0.0)$ & $1(0.3)$ & 0.55 \\
Biliary ductal injury & $0(0.0)$ & $0(0.0)$ & 1.00 \\
Seeding & $1(1.0)$ & & 0.34
\end{tabular}

Values are presented as number (\%).

RFA, radiofrequency ablation; MTA, microwave thermosphere ablation. 


\section{Comparisons of recurrence-free survival and overall survival between RFA and MTA groups}

Comparisons of cumulative recurrence-free survival and overall survival curves between RFA and MTA groups are shown in Figure 3. Although no significant difference was seen in recurrence-free survival between groups (RFA vs. MTA, 3-year, 49\% vs. 57\%, $P=0.409)$, a significant difference in overall survival was evident (RFA vs. MTA, 3-year, $77 \%$ vs. $95 \%, P=0.029$ ).

\section{Factors contributing to local tumor progression and survival}

Results of uni- and multivariable analyses for factors contributing to local tumor progression are shown in Table 3. Although significant differences were detected in ablation procedure, tumor size, and subcapsular and exophytic tumors on univariable analyses, multivariable analysis revealed ablation procedure and tumor size as independent factors. Results of uni- and multivariable analyses for factors contributing to survival are shown in Table 4. Uni-and multivariable analyses revealed ablation procedure and Child-Pugh score as factors significantly associated with survival.

\section{Comparison of complication between RFA and MTA}

No patient deaths occurred within 30 days after ablation. A comparison of complication profiles between RFA and MTA groups is shown in Table 5. Although no significant difference in major complication rate was seen between groups (RFA vs. MTA, $2 \%$ vs. $2 \%, P=0.74)$, the total complication rate was significantly lower for MTA (8\%) than for RFA $(14 \%, P<0.05)$, particularly for bile duct injury ( $3 \%$ vs. $9 \%$, respectively; $P<0.05$ ).

\section{DISCUSSION}

This retrospective cohort study evaluated whether a next-generation MTA for small HCC could safely improve local tumor control compared to RFA. In our clinical practice, as MTA was introduced in December 2017, and RFA was fully replaced by MTA from September 2018, the RFA group represents historical controls. As a result, the fact that local tumor progression rate was significantly reduced after introducing MTA for HCC in our clinical practice is noteworthy.

Regarding the comparison of local tumor control between RFA and conventional MWA, Facciorusso et al. ${ }^{12}$ demonstrated in a meta-analysis that the overall local tumor progression rate was similar between conventional MWA and RFA groups (odds ratio, 1.01; $95 \% \mathrm{Cl}, 0.53-1.87 ; P=0.98)$. Poulou et al. ${ }^{13}$ indicated in their review article that the results concerning local disease control rates with conventional MWA and RFA remain controversial. Clinical data about local tumor control are lacking for MTA. Takahashi et al. ${ }^{14}$ reported that the short-term local tumor progression rate compared favorably with that reported for RFA and other conventional MWA technologies in the literature. However, Suwa et al. ${ }^{15}$ could not identify a significant difference in local tumor progression rate between RFA and MTA groups in a short-term observation of a limited number of patients (log-rank test, $P=0.804$, 1-year, 5.2 vs. 6.9\%). The present study was able to show that the local tumor progression rate was significantly lower in the MTA group than in the RFA group (log-rank test, $P<0.001$, 3-year, 22\% vs. $8 \%$ ).

Tumor location is one potential factor influencing the technical success and complications of RFA. Ablation for a perivascular tumor carries higher risks of injuring Glisson's sheath and achieving incomplete ablation because of heat sink effects, while ablation in a subcapsular location increases the difficulty of electrode placement and carries a higher risk of complications such as seeding or injuring adjacent organs. Lai et al. ${ }^{16}$ indicated that a subcapsular location represents a possible risk factor for local tumor progression after RFA on meta-analysis, and whether a perivascular location influences the incidence of local tumor progression remains controversial. In the present study, the local tumor progression rate of MTA for subcapsular tumor was significantly lower than that of RFA. This result suggests that MTA should be applied for subcapsular HCCs in place of RFA. Regarding a perivascular location, An et al. ${ }^{17}$ reported that MWA tended to exhibit better local tumor control than RFA for small perivascular HCCs, although the difference was not significant $(P=0.116)$. The present study likewise failed to show any significant difference in local progression rate between RFA and MTA for perivascular HCC. The reason may be attributable to the fact that MTA was still slightly affected by heat sink effects. Further study is needed to clarify whether MTA can reduce the risk of local tumor progression after ablation for perivascular HCCs. Our better local control of tumor with MTA compared to RFA, particularly for subcapsular tumors, may have been attributable to reliable coagulation and a larger ablated margin rather than to reduced susceptibility to heat sink effects from peritumor vessels, artificial pleural effusion or ascites. 
Regarding the comparison of safety between RFA and conventional MWA, a meta-analysis by Facciorusso et al. ${ }^{12}$ demonstrated that major complications tended to be more frequent in MWA patients, although not significantly (odds ratio, 1.63; $95 \% \mathrm{Cl}, 0.88-$ 3.03; $P=0.12$ ). Comparing safety between RFA and MTA, Suwa et al. ${ }^{15}$ reported no significant differences in incidence rates of complications between groups (MTA vs. RFA, $13.6 \%$ vs. $14.5 \%$ ). However, in the present study, the total incidence of complications was significantly lower with MTA than with RFA, particularly for bile duct injury. This result was attributed to the high predictability of the ablation zone. Planning with accurate prediction of the ablation zone would seem likely to achieve safer ablation.

Among factors potentially associated with local tumor progression in RFA, tumor size is the only significant predictor. ${ }^{2}$ In the present study, not only tumor size but also treatment procedure were factors independently contributing to local tumor progression (MTA, $P<0.001 ;$ HR, $0.277 ; 95 \% \mathrm{Cl}, 0.155-0.494)$. Subcapsular and exophytic tumors were significant factors on univariable analysis, but not on multivariable analysis. These location factors would probably be confounders for tumor size.

In the present study, no significant difference in recurrence-free survival was seen between RFA and MTA groups (RFA vs. MTA, 3 -year, $49 \%$ vs. $57 \%$ ). Kim et al. ${ }^{18}$ demonstrated that the cumulative recurrence rate in patients with early-stage $\mathrm{HCC}$ who received curative treatment such as RFA or resection was around $50 \%$ at 3 years. As most recurrent HCC after curative treatment is ectopic, MTA cannot be said to have the ability to decrease multicentric or metastatic recurrences.

Regarding the comparison of overall survival between RFA and conventional MWA, Facciorusso et al. ${ }^{12}$ demonstrated in their meta-analysis that the overall survival rate after RFA tended to be higher, without showing a significant difference. Poulou et al. ${ }^{13}$ also indicated in their review article that survival rates were generally comparable between MWA and RFA groups, within the range of $68-100 \%$ after the first year and $24-78 \%$ after the fourth year. In the present study, the overall survival rate after MTA was significantly higher than that after RFA. Furthermore, treatment procedure was an independent factor contributing overall survival. Sala et al..$^{19}$ reported that initial complete response without local tumor progression to percutaneous ablation is associated with an improved survival in both Child-Pugh class A and B patients with nonsurgical HCC. As the local tumor progression rate after MTA was significantly lower than that after RFA, MTA might improve the prognosis over RFA. In the present study, however, as the proportion of liver cirrhosis and AFP level were lower in the MTA group than in the RFA group, better prognosis after MTA may be expected.

The present study showed several limitations. First, as the present study was a single-center, retrospective study, the potential for selection bias is unavoidable. A larger-scale randomized trial is needed to validate our results. Second, patient recruitment periods differed between the MTA and RFA groups. In particular, significant differences in proportions of perivascular tumor, liver cirrhosis, and etiology were seen between groups. Comparison after matching for important characteristics is therefore required. Third, local tumor control and safety of MTA in large HCCs $>3 \mathrm{~cm}$ in diameter could not be evaluated in the present study. Izzo et al. ${ }^{20}$ suggested in a review article that MWA should be considered the technique of choice in selected patients, when the tumor is $\geq 3 \mathrm{~cm}$ in diameter. Future studies should clarify whether MTA should be applied to large $\mathrm{HCC} \geq 3 \mathrm{~cm}$ in diameter.

In conclusion, this next-generation MTA for small HCC provided safer and more curative treatment than RFA within a shorter ablation time. MTA can also reduce the burden on not only patients, but also medical staff through this shorter ablation time. MTA has potential to replace RFA for small HCC.

\section{Authors' contribution}

Study concept and design: Hideyuki Tamai; Data collection: Hideyuki Tamai and Jumpei Okamura; Data analysis and interpretation: Hideyuki Tamai and Jumpei Okamura; Drafting of the article: Hideyuki Tamai; Critical revision of the article: Hideyuki Tamai and Jumpei Okamura; Final approval of the version to be published: all authors.

\section{Conflicts of Interest}

The authors have no conflicts to disclose.

\section{REFERENCES}

1. Ahn KS, Kang KJ. Appropriate treatment modality for solitary small hepatocellular carcinoma: radiofrequency ablation vs. resection vs. transplantation? Clin Mol Hepatol 2019;25:354-359.

2. European Association for the Study of the Liver. EASL clinical practice guidelines: management of hepatocellular carcinoma. J Hepatol 2018;69:182-236.

3. Kokudo N, Takemura N, Hasegawa K, Takayama T, Kubo S, Shimada M, et al. Clinical practice guidelines for hepatocellular carcinoma: the Japan Society of Hepatology 2017 (4th JSH-HCC guidelines) 
2019 update. Hepatol Res 2019;49:1109-1113.

4. Crocetti L, de Baere T, Lencioni R. Quality improvement guidelines for radiofrequency ablation of liver tumours. Cardiovasc Intervent Radiol 2010;33:11-17.

5. Lencioni R. Loco-regional treatment of hepatocellular carcinoma. Hepatology 2010;52:762-773.

6. Lubner MG, Brace CL, Hinshaw JL, Lee FT Jr. Microwave tumor ablation: mechanism of action, clinical results, and devices. J Vasc Interv Radiol 2010;21(8 Suppl):S192-S203.

7. Alonzo M, Bos A, Bennett S, Ferral H. The Emprint ${ }^{\mathrm{TM}}$ ablation system with Thermosphere ${ }^{\mathrm{TM}}$ technology: one of the newer next-generation microwave ablation technologies. Semin Intervent Radiol 2015;32: 335-338.

8. Vogl TJ, Basten LM, Nour-Eldin NA, Kaltenbach B, Bodelle B, Wichmann $\mathrm{JL}$, et al. Evaluation of microwave ablation of liver malignancy with enabled constant spatial energy control to achieve a predictable spherical ablation zone. Int J Hyperthermia 2018;34:492-500.

9. Lencioni R, de Baere T, Martin RC, Nutting CW, Narayanan G. Image-guided ablation of malignant liver tumors: recommendations for clinical validation of novel thermal and non-thermal technologies - a Western perspective. Liver Cancer 2015;4:208-214.

10. Shimizu R, Tamai H, Ida Y, Maeshima S, Shingaki N, Maekita T, et al. Feeding artery ablation before radiofrequency ablation for hepatocellular carcinoma may reduce critical recurrence. JGH Open 2021;5:478-485.

11. Ahmed M, Solbiati L, Brace CL, Breen DJ, Callstrom MR, Charboneau JW, et al. Image-guided tumor ablation: standardization of terminology and reporting criteria--a 10-year update. J Vasc Interv Radiol 2014;25:1691-1705.e4.

12. Facciorusso A, Di Maso M, Muscatiello N. Microwave ablation versus radiofrequency ablation for the treatment of hepatocellular car- cinoma: a systematic review and meta-analysis. Int J Hyperthermia 2016;32:339-344.

13. Poulou LS, Botsa E, Thanou I, Ziakas PD, Thanos L. Percutaneous microwave ablation vs radiofrequency ablation in the treatment of hepatocellular carcinoma. World J Hepatol 2015;7:1054-1063.

14. Takahashi H, Kahramangil B, Berber E. Local recurrence after microwave thermosphere ablation of malignant liver tumors: results of a surgical series. Surgery 2018;163:709-713.

15. Suwa K, Seki T, Tsuda R, Yamashina M, Murata M, Yamaguchi T, et al. Short term treatment results of local ablation with water-cooled microwave antenna for liver cancer: comparison with radiofrequency ablation. Mol Clin Oncol 2020;12:230-236.

16. Lai ZC, Liang JY, Chen LD, Wang Z, Ruan SM, Xie XY, et al. Do hepatocellular carcinomas located in subcapsular space or in proximity to vessels increase the rate of local tumor progression? A metaanalysis. Life Sci 2018;207:381-385.

17. An C, Li WZ, Huang ZM, Yu XL, Han YZ, Liu FY, et al. Small single perivascular hepatocellular carcinoma: comparisons of radiofrequency ablation and microwave ablation by using propensity score analysis. Eur Radiol 2021;31:4764-4773.

18. Kim J, Kang W, Sinn DH, Gwak GY, Paik YH, Choi MS, et al. Substantial risk of recurrence even after 5 recurrence-free years in early-stage hepatocellular carcinoma patients. Clin Mol Hepatol 2020;26:516-528.

19. Sala M, Llovet JM, Vilana R, Bianchi L, Solé M, Ayuso C, et al. Initial response to percutaneous ablation predicts survival in patients with hepatocellular carcinoma. Hepatology 2004;40:1352-1360.

20. Izzo F, Granata V, Grassi R, Fusco R, Palaia R, Delrio P, et al. Radiofrequency ablation and microwave ablation in liver tumors: an update. Oncologist 2019;24:e990-e1005. 